\title{
Thermal Performance Evaluation of a Direct Absorption Flat Plate Solar Collector (DASC) using $\mathrm{Al}_{2} \mathrm{O}_{3}-\mathrm{H}_{2} \mathrm{O}$ Based Nanofluids
}

\author{
Vivek Verma ${ }^{1}$, Lal Kundan ${ }^{2}$ \\ ${ }^{1}$ Mechanical Engineering Department, Thapar University (Patiala)-147004, India \\ ${ }^{2}$ Mechanical Engineering Department, Thapar University (Patiala)-147004, India
}

\begin{abstract}
Due to the growing demand of energy and lesser availability of fossil fuels there is a shift in our energy concern towards renewable energy sources. There is no doubt that from all the available sources, solar energy is the best option with its minimum environmental impact. Now a days different types of solar collectors are widely used to harvest solar energy. It has been found that performance of the solar collector depends upon the characteristics of the working fluid which is used to harvest solar energy in solar collector. In the present work the effect of $\mathrm{Al}_{2} \mathrm{O}_{3}-\mathrm{H}_{2} \mathrm{O}$ based nanofluids on the direct absorption type solar collector has been investigated experimentally. Nanofluids are the new class of the fluids with their improved properties over the host/conventional fluids. The volume fraction of $\mathrm{Al}_{2} \mathrm{O}_{3}$ nanoparticles used is $0.005 \%$ and $0.05 \%$. Efficiency of the collector is calculated for different mass flow rates $(60,80,100 \mathrm{ml} / \mathrm{hr})$ of $\mathrm{Al}_{2} \mathrm{O}_{3}-\mathrm{H}_{2} \mathrm{O}$ based nanofluids. From the results obtained by performing experiments, it has been found that collector efficiency increases about to 3$4 \%$ when $\mathrm{Al}_{2} \mathrm{O}_{3}-\mathrm{H}_{2} \mathrm{O}$ nanofluids are used as compared to simple water. Comparison of the collector efficiency for different mass flow rate and different concentrations are done. ASHRAE [4] standards were followed while performing all the experiments.
\end{abstract}

Keywords: Nanofluids, ASHRAE, Volume fraction, Efficiency, Collectors etc.

\section{INTRODUCTION}

Limited availability of fossil fuels and environmental problems associated with them have emphasized the need for new sustainable energy supply options that use renewable energy. Everyday sun radiates enormous amount of energy and the hourly solar flux incident on the earth's surface is greater than all of human consumption of energy in a year [1]. So, problem lies in efficiently collecting and converting this energy into some useful form. The conversion of solar energy into heat is done with the help of solar collectors. Most commonly used collectors are simple in construction and are flat plate type collectors. New classes of collectors which are used to increase the efficiency of the collectors are direct absorption solar collector (DASC) [2]. The DASC's were firstly proposed in the mid 1970's but the major problem faced by these collectors was the poor absorption properties of conventional fluids used in these collectors. By the development of new class of fluids known as nanofluids [3] which show improved properties over the conventional fluids, these type of collectors can gain importance. In conventional type of flat plate solar collectors they are encountered with three resistances whereas in case of direct absorption type solar collector (DASC), these three resistances are reduced to one. The major problem associated with conventional collectors using micro or millimeter sized particles is their rapid settling. These problems were least observed with the nanofluids. Nanofluids are new class of fluids in which nanometer sized $(1-100 \mathrm{~nm})$ particles of metal/ nonmetals/ metal oxides etc. are dispersed in conventional fluids. As we move towards the nanometer scale, it has been found that the properties of the suspension get changed drastically. Based on review of the reported research work, the attempt has been made to investigate the variation in collector efficiency using nanofluids.

\section{NANOFLUID BASED SOLAR COLLECTOR}

As Nanofluid based solar collectors are not available commercially, so in this section we are going to discuss the assumptions and the choices we made in designing the solar collector for this specific application. As mentioned above nanofluids are the fluids made by dispersing nanometer size metal/non metal/oxides particles in the conventional fluids. So first of all we made the choice of the base fluid to be used in the nanofluids. Commonly used base liquids are water, oil, ethylene glycol etc. The choice between these liquids is determined by the operating temperatures of the solar collectors since, our collector is a flat plate solar collector which operates between $\left(0^{\circ} \mathrm{C}-100^{\circ} \mathrm{C}\right)$ (i.e considered as low temperature range solar collector). So, taking this into consideration it has been decided to use distilled water as base fluid, which is cost effective also. In the next step selection of the nanopowder is done. Although, in market a range of different type of nano-powders is available, but its use for a particular application depends upon the factors like; easy availability, cost and comparatively improved properties. So it has been decided to use $\mathrm{Al}_{2} \mathrm{O}_{3}$ nanopowder or alumina powder for this particular application. The dispersion of nanopowder in the base fluid is done with the help of probe type 
sonicator (Oscar Ultrasonicators) and before each test run sonication is done for 2 hours to ensure the sooth and uniform dispersion of the nanoparticles in the base fluid. The concentration of the nanoparticles in the nanofluids is a very important parameter in the absorption of the solar energy. It was analyzed that a very high concentration results in rapid settling of the nanoparticles and too low concentration results in the decrease in the absorption of solar energy. So, it was decided to use optimum concentration which will increase the absorption of solar energy by solar collector and at the same time it will decreases the settling rate of nanoparticles. The Dimensions of the collector were chosen to increase the absorption of solar energy with the minimum requirement of the nanofluids. The effect on the performance of the solar collector with variation of mass flow rate of nanofluids and with volume fraction of nanoparticles has been studied in this experiment.

\section{EXPERIMENTAL SET-UP}

\section{A. Dimensions and material of construction of Direct absorption solar collector}

The effective area of the absorber plate is $240 \times 240 \mathrm{~mm}$ and the total area of the collector including wooden box is $300 \times 300 \mathrm{~mm}$. The absorber plate was painted black in order to increase it's absorption properties. In order to minimize the losses glass wool and thermocol insulation are provided at the side's walls and at the bottom. Outer casing of the collector is made of wood. The glazing used is low reflectance glass with transmittance percentage of $86.3 \%$.

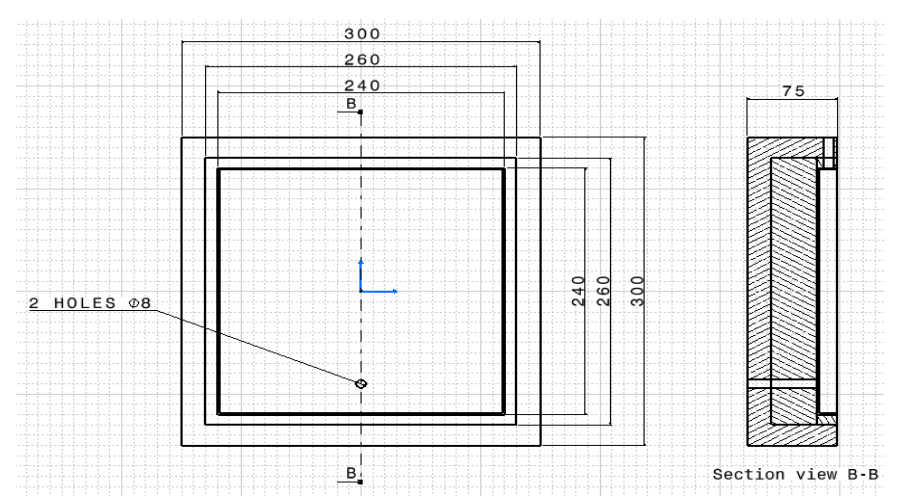

Fig.1 Dimensions of the flat plate solar collector (All dimensions in $\mathrm{mm}$ )

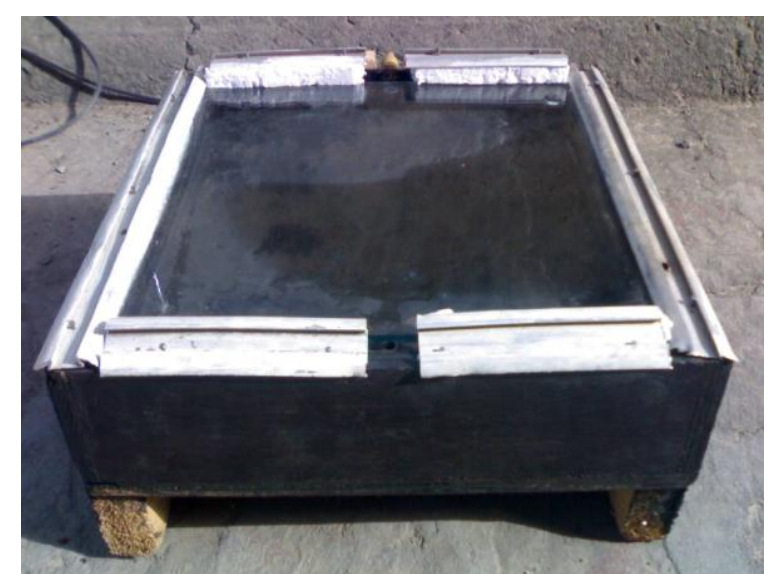

Fig. 2: Actual view of Direct absorption solar collector

The absorber plate is black painted copper plate and the size of collector is kept small in order to reduce the use of nanofluids. The flow of the nanofluids is controlled through the infusion set.

\section{B. Material used}

$\mathrm{Al}_{2} \mathrm{O}_{3}$ nanoparticles were purchased from reinste nanoventures pvt. limited.The specifications are:

particle shape:spherical

average parcticle size: $40 \mathrm{~nm}$

specific surface: $>10 \mathrm{~m}^{2} / \mathrm{g}$

purity: $>99.8 \%$

Double distilled water was used as the base fluid throughout the preparation of the nanofluids. 


\section{Preparation of $\mathrm{Al}_{2} \mathrm{O}_{3}$ nanofluids at different concentrations}

Firstly the weight of nanoparticles is calculated for different concentrations.weight can be calculated using this expression as:

$\mathrm{X}[5]=\mathrm{V}_{\mathrm{P}} / \mathrm{V}_{\text {eff }}$

Where, $V_{P}=W_{P} / \rho_{P}$

$\mathrm{V}_{\text {eff }}[10]=\mathrm{V}_{\mathrm{P}}+\mathrm{V}_{\mathrm{f}}, \mathrm{V}_{\mathrm{f}}=\mathrm{W}_{\mathrm{f}} / \rho_{\mathrm{f}}$

Quantity of Base fluid (Water), $\mathrm{V}_{\mathrm{f}}=500 \mathrm{ml}$

Density of $\mathrm{Al}_{2} \mathrm{O}_{3}$ particles, $\rho_{\mathrm{P}}=3.9 \mathrm{gm} / \mathrm{cm}^{3}$

Density of water, $\rho_{\mathrm{f}}=1000 \mathrm{~kg} / \mathrm{m}^{3}$

Tab. II:Mass of nanoparticles required for different volume concentartions

\begin{tabular}{|c|c|c|c|}
\hline $\begin{array}{c}\mathrm{X} \\
\text { (wt.\%) }\end{array}$ & 0.005 & 0.05 & 0.1 \\
\hline $\begin{array}{c}\mathrm{W}_{\mathrm{p}} \\
(\mathrm{gm})\end{array}$ & .09912 & 0.99174 & 1.98448 \\
\hline
\end{tabular}

In order to prepare $\mathrm{Al}_{2} \mathrm{O}_{3}$ nanofluids, sonication [8] of the nanoparticles in the base fluid is done for different times $(2-5 \mathrm{hrs})$.

\section{Experimental procedure}

The schematic of the experiment is shown in Fig.2. The solar collector was eperimentally investigated at Thapar University patiala, India. The flow rate of the nanofluids is controlled through the infusion set. Small collector size is used in order to reduce the quantity of nanofluids used. Nanofluids were stored in a bottle which was capable to supply desired mass flow rate of nanofluid.The inlet and outlet temperatures were measured with the help of digital thermometer (Mex Tech). Pyranometer (Kipp and zonen) [9] was used for calculating the global solar irradiation values. Various results in the graphical form were plotted between collector efficiency vs mass flow rate, temperature difference vs time and efficiency vs time.

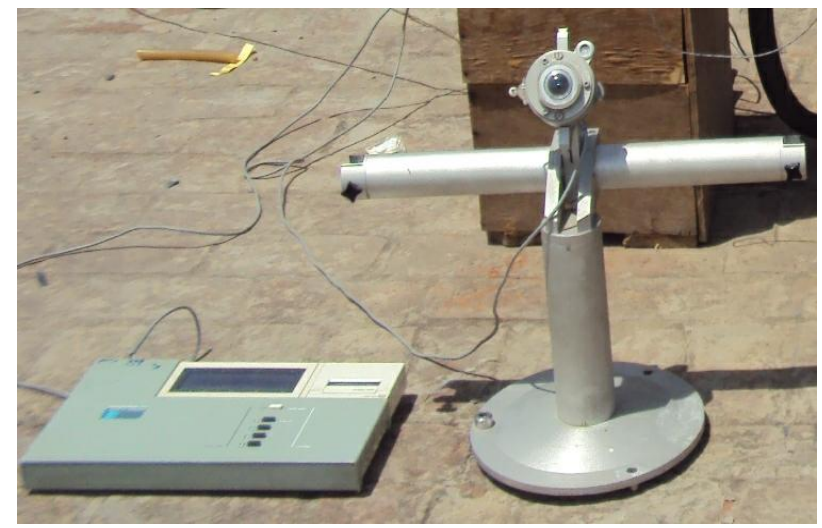

Fig. 3 Kipp and zonen pyranometer

\section{E. Method of testing of solar collector}

ASHRAE standards 93-77[4,8] were followed for testing the thermal performance of DASC. The thermal performance of DASC is determined by calculating the instantaneous collector efficiency for different mass flow rates and at different temperature difference. Mathmatical relation used to determine the collector efficiency is given as following:

Collector efficiency [6]

$\eta=\mathrm{m} \mathrm{C}_{\mathrm{eff}}\left(\mathrm{T}_{2}-\mathrm{T}_{1}\right) / \mathrm{G}_{\mathrm{T}} \mathrm{A}$

Mass flow rate [7]

$\mathrm{m}=\rho_{\text {eff }} \times \mathrm{A} \times \mathrm{v}$

Effective density of nanofluid

$\rho_{\text {eff }}=\left(1-\varphi_{p}\right) \rho_{\mathrm{f}}+\varphi_{\mathrm{p}} \rho_{\mathrm{p}}$

Volume fraction

$\varphi_{\mathrm{p}}=\mathrm{V}_{\mathrm{p}} /\left(\mathrm{V}_{\mathrm{p}}+\mathrm{V}_{\mathrm{f}}\right)$

Specific heat [7] 
$\mathrm{C}_{\text {eff }}=\left\{\left(1-\varphi_{\mathrm{p}}\right) \rho_{\mathrm{f}} \mathrm{c}_{\mathrm{f}}+\varphi_{\mathrm{p}} \rho_{\mathrm{p}} \mathrm{c}_{\mathrm{p}}\right\} / \rho_{\mathrm{eff}}$

where

$\eta=$ Instantaneous efficiency $(\%)$

$\mathrm{m}=$ Mass flow rate of the working fluid $(\mathrm{ml} / \mathrm{hr})$.

$\mathrm{C}_{\text {eff }}=$ Effective specific heat of the nanofluids $\left(\mathrm{kj} / \mathrm{kg}^{\circ} \mathrm{c}\right)$.

$\mathrm{T}_{2}=$ Outlet Temperature of the working fluid $\left({ }^{\circ} \mathrm{c}\right)$.

$\mathrm{T}_{1}=$ Inlet Temperature of the working fluid $\left({ }^{\circ} \mathrm{c}\right)$.

$\mathrm{G}_{\mathrm{T}}=$ Global solar irradiation

$\mathrm{A}=$ Area of the absorber plate $\left(\mathrm{m}^{2}\right)$

$\rho_{\text {eff }}=$ Density of the nanofluids $\left(\mathrm{kg} / \mathrm{m}^{3}\right)$

$\varphi_{\mathrm{p}}=$ Volume fraction of nanoparticle

$\rho_{\mathrm{p}}=$ Density of nanoparticles

$\mathrm{V}_{\mathrm{P}}=$ Volume of the nanoparticles

$\mathrm{V}_{\mathrm{f}}=$ Volume of the base fluid

\section{RESUlTS AND DiscuSSIONS}

A. Variation of collector efficiency and temperature difference for water at different mass flow rates

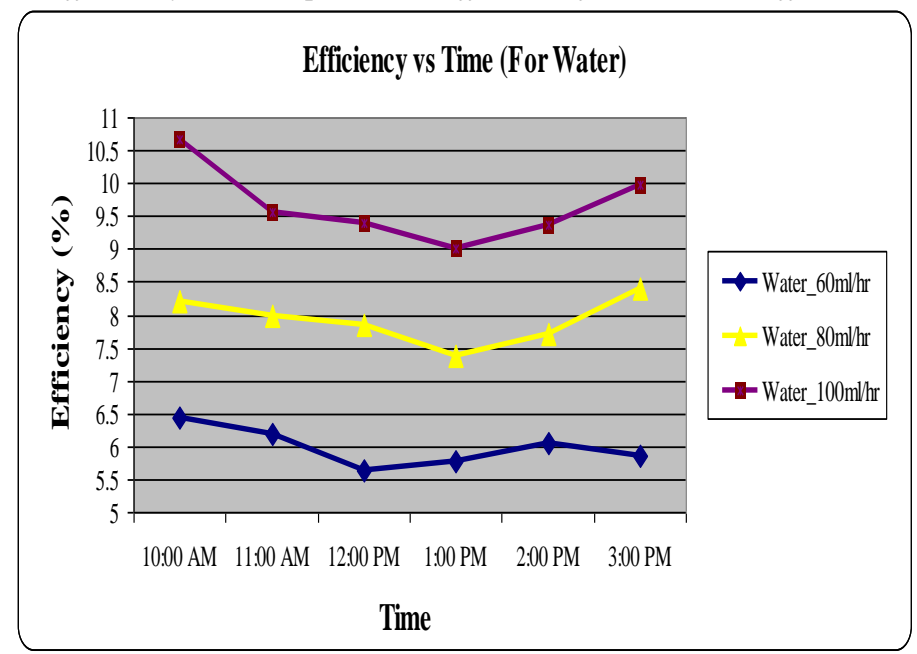

Fig. 4: Collector efficiency for water at different mass flow rates

Figure 4, shows the variation of collector efficiency at different mass flow rates and at different instants of time. As mass flow rate is increasing collector efficiency is also increasing due to the higher numerical value of the mass flow rate. Also the graph shows the same pattern around 1:00 pm because of higher value of global solar irradiation which is in denominator of the collector efficiency expression.

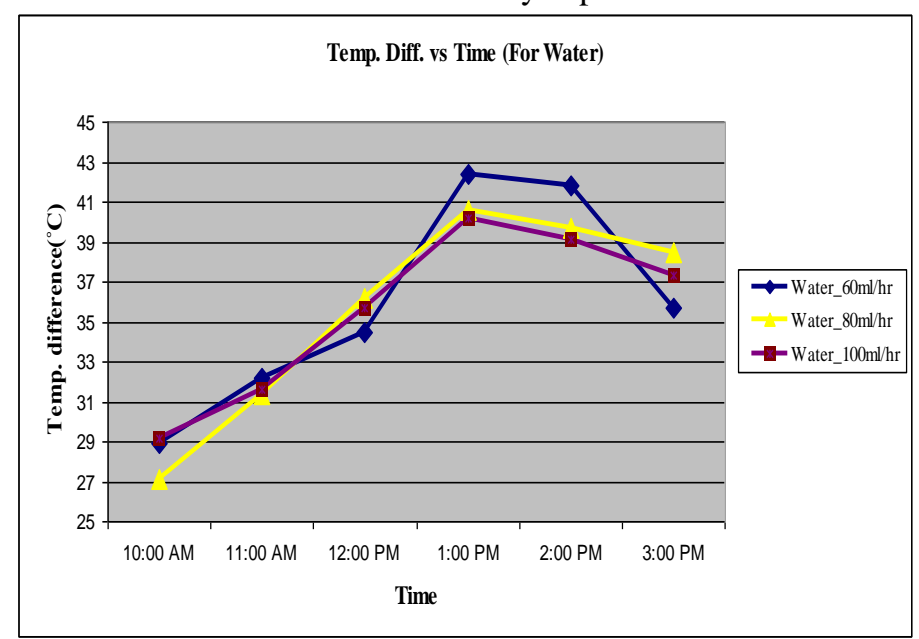

Fig 5: Variation of temperature difference for different mass flow rates at different instants of time 
Figure 5 clearly shows the increase of temperature difference with low mass flow rate because at low mass flow rates heat absorption by the working fluid is high. Maximum temperature difference is obtained at near about $1: 00 \mathrm{pm}$.

\section{B. Variation of collector efficiency and temperature difference for $\mathrm{Al}_{2} \mathrm{O}_{3}-\mathrm{H}_{2} \mathrm{O}$ based nanofluids for $0.05 \%$ volume concentration}

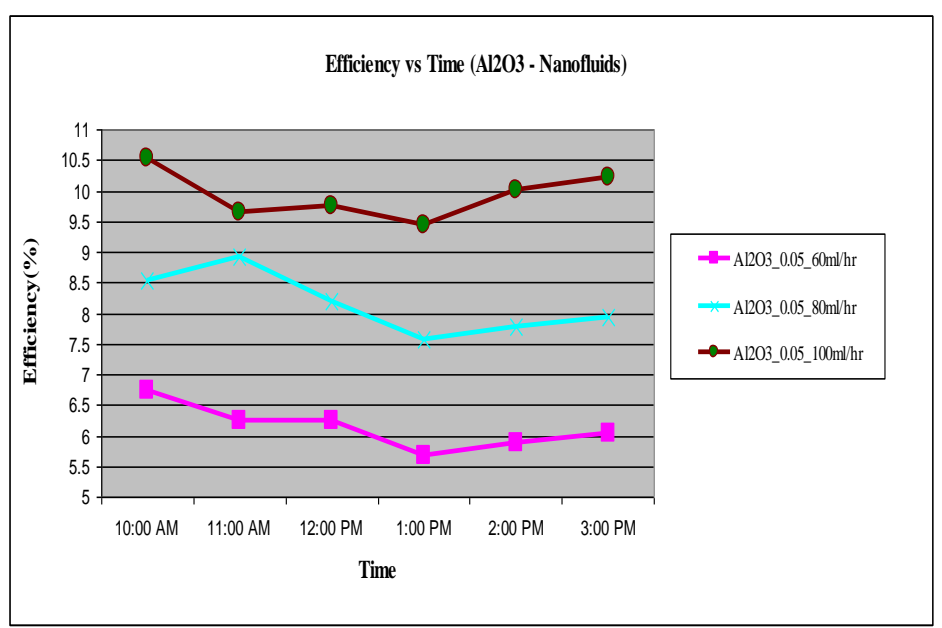

Fig. 6: Collector efficiency for $\mathrm{Al}_{2} \mathrm{O}_{3}-\mathrm{H}_{2} \mathrm{O}$ nanofluids for different mass flow rates at different instants of time.

From fig 6 the efficiency of the collector increases for the nanofluids as the mass flow rate increases. Minimum collector efficiency is obtained at 1:00 pm due to the higher value of global solar irradiation

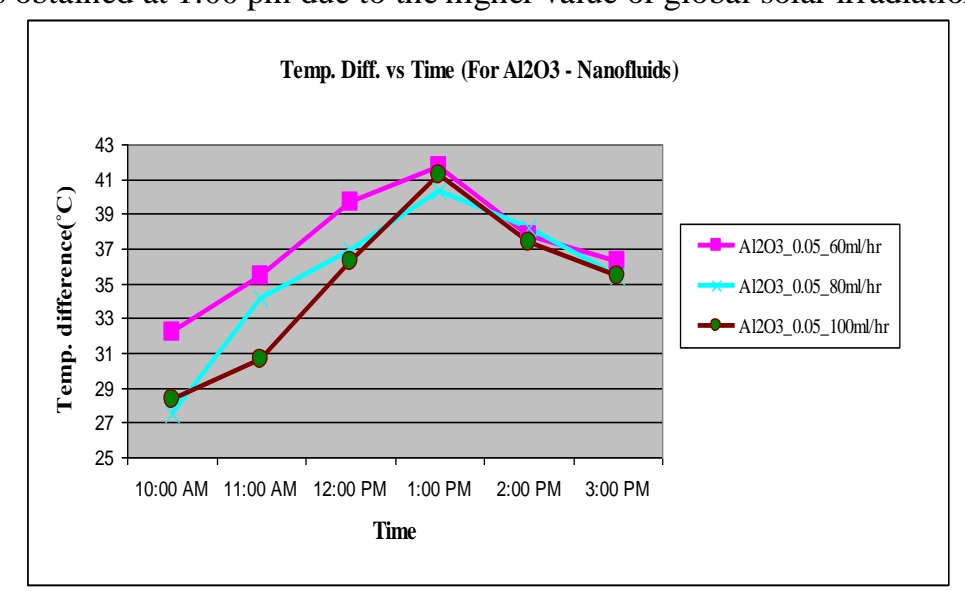

Fig. 7: Variation of temperature difference for $\mathrm{Al}_{2} \mathrm{O}_{3}$ for different mass flow rates at different instants of time

Figure 7 shows that for lower mass flow rates the temperature difference is higher and Maximum temperature difference is obtained near 1 and $2 \mathrm{pm}$.

\section{Comparison graphs for water and $\mathrm{Al}_{2} \mathrm{O}_{3}$ for different mass flow rates}

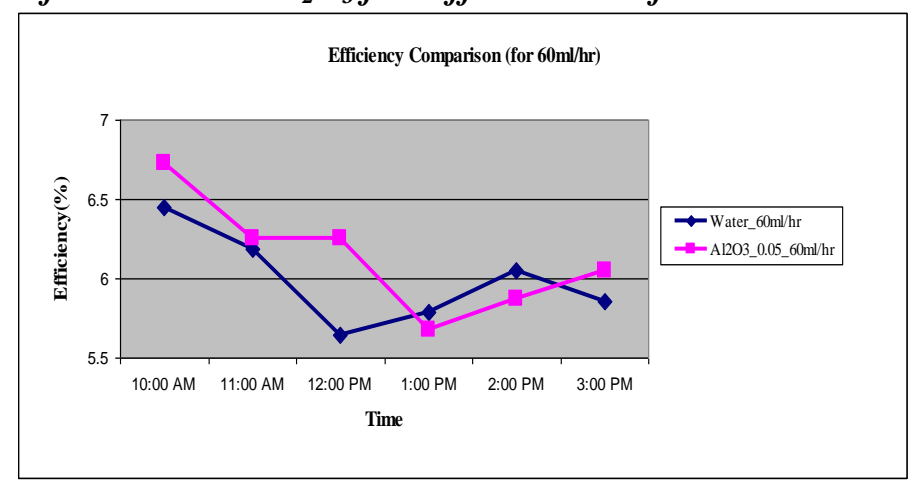

Fig. 8: Variation of efficiency of $\mathrm{Al}_{2} \mathrm{O}_{3}$ for $60 \mathrm{ml} / \mathrm{hr}$ at different instants of time 


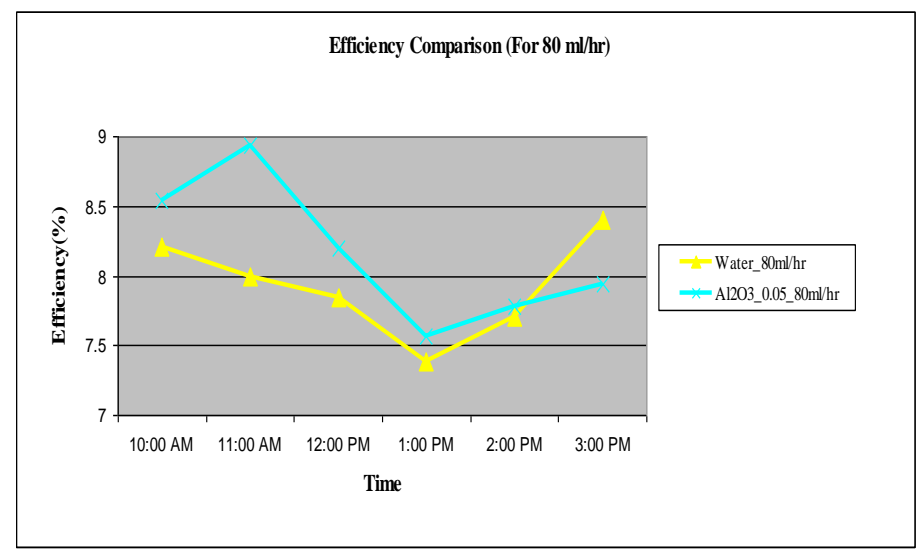

Fig. 9: Variation of efficiency of $\mathrm{Al}_{2} \mathrm{O}_{3}$ for $80 \mathrm{ml} / \mathrm{hr}$ at different instants of time

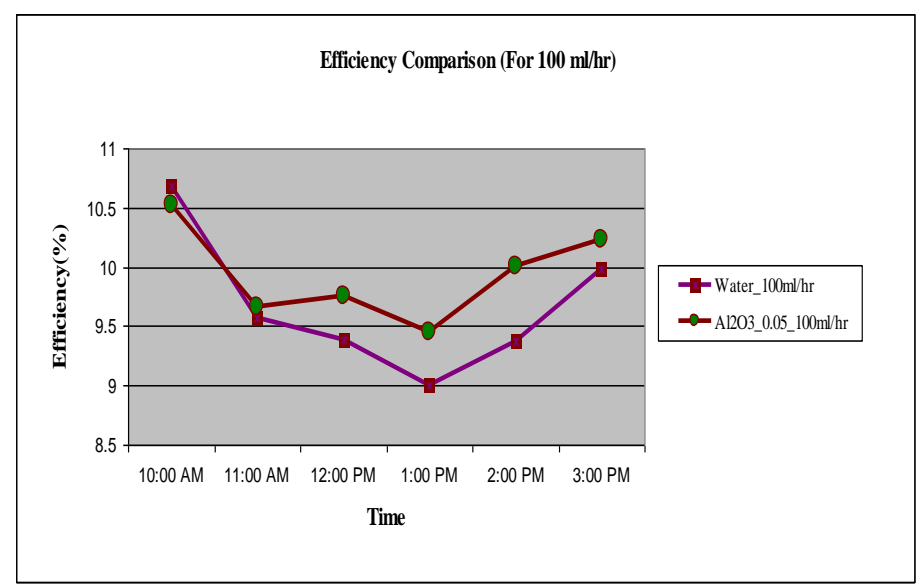

Fig.10: Variation of efficiency of $\mathrm{Al}_{2} \mathrm{O}_{3}$ for $100 \mathrm{ml} / \mathrm{hr}$ at different instants of time.

From Fig 8, Fig 9, Fig 10 it has been observed clearly that there is an increase in efficiency of the collector after using the nanofluids. Although, effciency is not constant with time. There is a slight decrease in the efficiency near at 1:00 PM due to the higher value of global solar irradiation and smaller size of the collector. It has been also observed that as the mass flow rate of the nanofluids is increased, the efficiency of the solar collector also increases. Where as, with increase in the mass flow rate the temperature difference decreases. This can be due to the reason that with lower mass flow rate nanofluid has more time to absorb solar radiations and gain more heat.

\section{CONCLUSION}

The effect of $\mathrm{Al}_{2} \mathrm{O}_{3}-\mathrm{H}_{2} \mathrm{O}$ based nanofluids as absorbing medium in a direct absorption solar collector is studied. Effect of mass flow rate, nanoparticles mass fraction is studied .The results showed that at $0.05 \%$ (wt $\%$ ) nanofluid increases the efficiency of the collector by 3-5\%. So there is scope to improve the harvesting of the solar energy. It is suggested that higher efficiency of the collector can be obtained by minimizing the losses and preventing the settling of the nanoparticles. The size, shape and volume fraction of the nanoparticles in the nanofluid nanofluids effects directly the collector efficiency. More development in the nanofluids properties and their relevant use in the solar energy harvesting will leads to the more research in this field.

\section{REFERENCES}

[1] Garg.H.P, Prakash.J, Solar Energy Fundamental and Applications, Tata McGraw Hill, ISBN 0-07-463631-6, Page(35,46,116), 1997.

[2] Taylor A.R, Phelan E.P, Otanicar P.T, Walker A.C, Nguyen M,Trimble S, Ravi P, Applicability of Nanofluids in high flux solar collectors, Journal of Renewable and Sustainable Energy 3, 023104(2011).

[3] Das.K.S, Choi.S.U.S, YU.W, Pradeep.T, Nanofluids science and Technology, ISBN: 978-0-470-07473-2, Page(1-30).

[4] Draft ASHRAE Standards,Proposed standards77-93, Third Public Review (May 2009).

[5] Khanafer K, Vafai K, A Critical syntesis of thermophysical Characteristics of Nanofluids, International Journal of Heat and Mass transfer(Under Press), 2011.

[6] Sukhatme S.P, Solar energy Fundamental and Applications, Tata Mcgraw Hill Publication, ISBN:0-07-451946-8,PP-45-46,1984.

[7] Timofeeva V E, YU W, France M D, Singh D, Routbort L J, Nanofluids for heat transfer: An Engineering approach, Nanoscale research Letters ,6:182(2011).

[8] Choi S.U.S, Nanofluid Technology:Current Status and Future research, Energy Technology Division , Argonne National Laboratory, Sep28,1999. 
[9] Pyranometer CMP-11 from Kipp \& Zonen, http://users.du.se/ ffi/SERC/Hybrid/technical_data.htm

[10] Timofeeva V E, YU W, France M D, Singh D, Routbort L J, Nanofluids for heat transfer: An Engineering approach, Nanoscale research Letters,6:182(2011)

\section{AUTHORS}

First Author - Vivek verma, Master's of engineering (Thermal Engineering), Mechanical engineering department, Thapar University (Patiala)-147004, India,

Second Author - Lal Kundan, Master's of engineering (Thermal Engineering), Mechanical engineering department, Thapar University (Patiala) -147004, India, 